\title{
European Quality Assurance-A European Higher Education Area Success Story [Overview Paper]
}

\author{
Hanne Smidt
}

\section{Introduction}

The quality of higher education has proven to be at the heart of the setting up of a European Higher Education Area (Berlin Communiqué 2003)

The development and implementation of a Europe of knowledge or the European Higher Education Area has led at institutional, regional, national and European level to a wave or a tsunami of changes to policies, strategies and legal frameworks in a strive for balancing European collaboration and global competition. In 1999, ministers, stakeholder organisations and higher education institutions signed up to the aims and the action lines of the Bologna Process, ${ }^{1}$ and have since "adapted and adopted" the Bologna architecture to their cultural, political, social and economic contexts (Sursock and Smidt 2010). Research has shown that adaptations - not least when it comes to quality assurance policies and practices - at national and institutional level have led to both convergence and increased diversity, as higher education is closely intertwined with regional and national cultures (Sursock and Smidt 2010). Governments and European higher education institutions have been caught in a conundrum between adapting to joint European policies and frameworks and maintaining and highlighting their national/institutional and cultural uniqueness. One area where European and national and institutional implementation policies and practices is converging and diverging is in quality assurance, nevertheless it is a policy area that has emerged as one of the cornerstones of the Bologna architecture (Loukkola 2012).

\footnotetext{
${ }^{1}$ For the members of EU, several layers of reform agendas have been added by Europe 2020, the Modernisation Agenda and the High Level Group on the Modernisation of Higher Education.
}

H. Smidt ( $\square)$

European University Association, Brussels, Belgium

e-mail: hanne.smidt@telia.com

(C) The Author(s) 2015

A. Curaj et al. (eds.), The European Higher Education Area,

DOI 10.1007/978-3-319-20877-0_40 
Over the past twenty years, the history and the development of quality assurance prior to and within the Bologna Process have been tracked in a plethora of policy reports and research articles. ${ }^{2}$ The reports and the research indicate there were a number of drivers for the development of European quality assurance outside the Bologna Process e.g. massification, new public management, the development of private higher education institutions that occurred after the fall of the iron curtain, ${ }^{3}$ and the increased focus on creating a competitive European Higher Education system. For universities in Central and Eastern Europe, the post-iron curtain era meant radical changes and challenges that were far more profound than the in some countries controversial reforms introduced in the name of Bologna. Adapting to political change processes like the post-communist era, the Bologna Process - and for the member states of the European Union-the Modernisation Agenda has meant that European higher education institutions have had to navigate between tradition and renewal, and increasingly to respond to a growing demand for accountability and transparency in an ever more difficult funding environment. These pressures have in turn led to a need to develop a quality culture, while addressing the challenges of globalised higher education. A pressure that the sessions on quality assurance at the Future of Higher Education Conference in Bucharest in 2014 showed has to be work in continuous progress. The presentations and discussions also indicated that the perception of quality assurance is very multi-dimensional and contextual and that a gap exists in the view between professionals in quality assurance and academic staff and students. The presentations at the conference showed that quality assurance is applied very differently in Europe, as is reflected in the policies and practices in the European countries. Practices vary between accreditation driven systems and quality enhancements driven systems, and in some systems, the distinction between external and internal quality assurance is not evident for academics and administrative staff.

The conference confirmed that European quality assurance framework is key to the transformative European change agenda (Sursock 2012, pp. 247-265), and has a clear impact on the "European dimension". It also pointed out that in the institutional context quality assurance often is inward looking, and not all stakeholders perceive a clear difference between external and internal quality assurance. While transformation takes time (Smidt 2012, in Curaj et al.) Sursock points out that:

Too often, changes to external quality assurance are made with little consideration of other higher education policy developments or requirements or by focusing on a narrow set of education policy developments or requirements or by focusing on a narrow set of changes (e.g. evaluating whether institutions are developing a learning-outcome approach to

\footnotetext{
${ }^{2}$ The articles presented at the Future of Higher Education Researcher conference in Bucharest 2012 tracked and mapped the development and growth of quality assurance agencies, frameworks and practices at institutional, national and European level and interpreted quality assurance from a variety of stakeholder points of view (Curaj et al.). The present chapter will build on these.

${ }^{3}$ The fall of the Iron Wall led to a sharp rise in the provision of private higher education that led to the development of accreditation procedures to ensure quality, but not necessarily within QA agencies.
} 
teaching). And the changes to external QA, in turn, affect the way institutions carry out their internal QA processes. (Sursock 2012, p. 263 in Curaj et al.).

The evolving nature of the EHEA policy agenda has meant that the links between the different Bologna action lines have not necessarily been clear to the institutional actors (Sursock and Smidt 2010). The present introduction to the chapter on quality assurance will therefore discuss the following question. Why European quality assurance should be considered a success story? How does the revised ESG reflect recent developments in European higher education and support a much more integrated approach? What are the emerging challenges for European quality assurance, and which areas, based on the research presented at the conference, require further developments or progress?

\section{European Universities Consider Quality Assurance an Important Strategic Reform}

There was early agreement within the Bologna Process that European higher education institutions are responsible for the quality of European higher education as stated in the Berlin Communiqué (2003). The EUA Trends 2010 report that has tracked the first decade of implementation of the European Higher Education Area showed that European higher education institutions find quality assurance one of the most important reforms. European higher education institutions (HEIs) and European national rectors' conferences both considered that, alongside the Bologna structural reforms, quality assurance and quality assurance reforms/policies were the key policy change in the first Bologna decade. $60 \%$ of the responding higher education institutions in 2010 found that over the past ten years enhanced internal quality assurance processes had been the most important change, followed by enhanced cooperation with other HEIs (53\%) and more autonomy $43 \%$ (Sursock and Smidt 2010, p. 18). Furthermore, the HEIs answered that after strategic institutional development (78 \%), quality assurance (63\%) was considered the most important development followed closely by internationalisation $(61 \%)$. The forthcoming Trends 2015 report suggests that the importance of quality assurance and internationalisation seen from a strategic institutional point of view has increased even further over the past five years. The overall European results, however, cover large differences between countries. Countries that felt that internal quality assurance was not important in 2010 have made great progress by 2015 .

This raises the question as to why European universities consider quality assurance to be one of the most important Bologna reform, when there has been critique on the implementation of other Bologna action lines. Why do institutions approach quality assurance from a European perspective? There are a number of reasons for this.

First, the quality assurance agenda has been driven by the collaboration and continuous engagement of the four European stakeholder organisations: the 
European University Association (EUA), the European Association of Institutions in Higher Education (EURASHE), the European Student Union (ESU-formerly ESIB) and the European Network for Quality Assurance (ENQA). These four organisations established almost from the beginning of the Bologna Process a working relationship through the E4 group. Together-despite sometimes diverging opinions - they have developed a common platform for quality assurance: the European Standard and Guidelines (ESG) created and managed the European Quality Assurance Register (EQAR) and organised the European Quality Assurance Forum (EQAF). The combination of these initiatives created a pan-European stage for continuous discussion and exchanges of good practice between European, national and institutional policy makers and stakeholders like no other Bologna action line has.

Second, the four stakeholder organisations also have "walked the talk" by developing projects that have tracked and promoted the development and implementation of both external and internal quality assurance practices. The European stakeholder organisations have created fora where members have been able to discuss and develop recommendations with peers via individual or joint QA projects. The discussions and exchange of experience in these projects and their reports have helped to promote and inform the development of a quality culture in European higher education institutions, and simultaneously helped to track the development and helped to engage in communication with and between stakeholders at European, national and institutional level on the progress.

Third, the annual European Quality Assurance Forum (EQAF) has been a cornerstone in the communication within the European quality assurance community since 2006. It has been a major contribution to QA in higher education, and a flagship activity in this field (Loukkola 2012). EQAF provides a platform and an opportunity for the higher education and QA communities to follow, discuss, shape and anticipate developments in the area. The conferences have traditionally brought all the key actors in the field together: higher education institutions (leadership, QA responsible/practitioners and academics), staff from quality assurance agencies, students and European policy makers. EQAF keeps attracting all stakeholder groups and the theme of the 2014 forum indicates a shift in the view on quality assurance. The title: "Changing education - QA and the shift from teaching to learning" point to a move in focus from quality assurance policies and practices to an increased focus on the development of the core of the European Higher Education Area reforms: teaching and learning and the provision of student-centred learning. A move from form towards content.

Fourth, the training that thousands of academics are receiving as national and international evaluators and the staff engaged in quality assurance who work at institutional and national level on the development of policies and practices serve to promote quality assurance and spread good practices. Only one other action-line: internationalisation has created such transnational "educational" structures and communities through EAIE.

Other external change drivers that have promoted quality assurance include the impact of the rapidly expanding student numbers that in many European countries 
has brought a more utilitarian view of higher education than in previous generations of students, and has created a greater demand for accountability and transparency. The utilitarian point of view is also reflected in the increased focus on skills and employability in the EC. In many countries, this debate is progressively becoming interlinked with the debate on quality and quality assurance (e.g. the Danish committee on quality and relevance of higher education). While there is clearly a link between quality of education and employability, there is also a great danger in establishing a simplistic and linear connection between the two. There is a real danger that the essential "bildung" and the civic development aspects of higher education is overlooked if a purely utilitarian approach is adopted. If a simple and linear correlation is introduced, the process of diversification of higher education, providing access to education to students from all backgrounds throughout a student's life is often disregarded. If the goals of permeability, diversification and flexibility are ignored, then quality assurance can create conformity rather than innovation, and the overriding aim of creating a Europe of Knowledge for an increasingly diverse student population might be lost.

\section{Emerging Challenges for External Quality Assurance}

A whole new higher education profession and "industry" has grown around the development of external and internal quality assurance. Prior to 2000, only four European countries had quality assurance agencies (Loukkola 2012); today, ENQA has 39 members in 23 countries (ENQA 2014).

The rapid growth has been well-documented, and the literature on quality assurance shows that external or agency based quality assurance methodologies vary greatly. In many countries, external quality assurance has moved between a focus on programmes or institutions and between supporting quality enhancement (supporting the development of institutional quality cultures) or an accreditation approach that stresses compliance (Stensaker 2011; Sursock 2012; Loukkola and Sursock $^{4}$ 2014). The literature indicates that a dichotomy or a binary system with pendulum swings between accreditation and quality enhancement seems to have developed, but it also points to the fact that stakeholders tend to consider neither approach entirely successful over time. As the pendulum is ever moving, it is difficult to get an overview of the development of the constantly changing national external quality assurance systems or policies, and Stensaker and Sursock both indicate that external quality assurance is considered very much a national practice despite the large European community of practitioners and ENQA and EQAR. It appears that the European Standards and Guidelines (ESG) guide national and institutional practices for quality assurance, but the research presented at the

\footnotetext{
${ }^{4}$ In EUA, European University Association (2014). A Twenty-Year Contribution to Institutional Change.
} 
conference that the ESG is not commonly referenced or known outside the quality assurance community in many Bologna countries.

The four presentations at the conference indicated that quality assurance is applied very differently in Europe and that it is still work in progress. It was argued that (external) quality assurance easily promotes compliance, and that it is therefore a requirement for quality assurance constantly to re-address this through changing the methodology, thus supporting the pendulum swings. The articles in the present chapter support the observation that developments in both external and internal quality assurance (EQA and IQA) are in an almost permanent state of flux. Furthermore, the study presented by Szabo on the use of transnational or cross-border quality assurance (and where quality assurance meets internationalization) by a number of European higher education institutions shows that a variety of EQA is in use, but also indicates that cross-border quality assurance is so far not a common practice.

A key challenge both for external and internal quality assurance is to engage staff and students. Two of the articles (Geven and Maricut, Logermann and Leisyte, this volume) in this chapter show new research in an institutional context that suggest that many European HEIs yet have to comprehensively engage students and academics in ensuring high quality learning and teaching. The articles introduce new research on the perceptions and the involvement of staff and students in internal quality assurance and their research indicate that these groups tend to be largely unaware of the European or external dimension of quality assurance. The Logermann and Leisyte article suggests that more attention needs to be paid to the role of students in institutional quality assurance and further development of practices for the use of course evaluations.

Geven and Maricuţ show that evaluation overload in the Romanian context seriously undermines the benefits of quality assurance and that staff can become disengaged and fail to distinguish the difference between external and internal quality assurance. In fact, the opposite of a quality culture, a culture of disengagement is developing.

The Rutherford and Pickup article reflects the important role institutional research plays and the essential role quality assurance plays in all parts of a successful student experience. It provides an important reflection on achieving a balance between supporting students as they progress and developing processes for enhancing the experience of all students groups.

\section{European Quality Assurance "Work in Progress"-The Revised European Standards and Guidelines}

The Berlin Communiqué recognised that quality assurance:

should include: a definition of the responsibilities of the bodies and institutions involved; evaluation of programmes or institutions, including internal assessment, external review, 
participation of students and the publication of results; a system of accreditation, certification or comparable procedures, and international participation, cooperation and networking. (Berlin Communiqué 2003)

The core elements - defined responsibilities for the involved stakeholders, procedures for evaluation and accreditation, external/international reviews, student participation and networking, etc.-were quickly and successfully translated by the E4 group into the "European Standards and Guidelines" (ESG), EQAR and EQAF. The ministers adopted the ESG in 2005 in Bergen; the annual networking forum, EQAF, held its first meeting in 2006; and the European Quality Assurance Register for Higher Education (EQAR) was established by the E4 group in 2008.

Once adopted, the implementation or rather the interpretation of the ESG in different contexts has been an on-going process, and there has been great variations in how and how clearly the ESG has been adhered and referred to both in an institutional context and national context (See the Examining Quality Culture reports, EUA 2009-2012). However, the 2011 E4 study: "Mapping the Implementation and Application of the ESG" (ENQA 2011) - concluded that the ESG had proved to be a major achievement of the Bologna Process. They were found to be applicable in different contexts and have had an impact on both the institutional and national QA processes and on the work carried out by quality assurance agencies (ENQA 2011, p. 6). The study found that the ESG have become the language or reference point that all stakeholders refer to, but also emphasized that the purpose and scope of the ESG had an in-built tension between being identified either as a reference document or as a compliance tool. This was one of the underlying reasons for the revision of the ESG; a further reason was to integrate quality assurance with the Bologna architecture and the development of learning and teaching. The FOHE researcher conference in 2012 supported the proposal for a revision.

The E4 group had from the outset intended the ESG to be "work in progress" (ENQA 2005) and there was an early understanding that the ESG would need to be analysed and reviewed as the European quality assurance landscape developed and changed. Given this context, the Bucharest Ministerial Communiqué invited the E4 Group (ENQA, ESU, EUA, and EURASHE) in cooperation with Education International (EI), BUSINESSEUROPE and the European Quality Assurance Register for Higher Education (EQAR) to prepare an initial proposal for a revised ESG "to improve their clarity, applicability and usefulness, including their scope". The revision process has included several consultation rounds involving both the key stakeholder organisations and ministries. The proposal reflects a consensus among all the organisations involved on how to take forward quality assurance in the European Higher Education Area. It thus supports the principle that the basis of development in quality assurance is a close collaboration and discussions within and between all stakeholder groups. The proposal for the revised EGS has maintained its structure and the three sections on internal and external quality assurance and on the quality assurance of external agencies (2014). 
A revised version of the ESG is proposed to the next ministerial conference in Yerevan in May 2015. The main discussions and revisions have essentially been introduced to Part 1 that presents the ESG for internal quality assurance, and now have a much clearly defined link to the whole Bologna framework:

The ESG are not standards for quality, nor do they prescribe how the quality assurance processes are implemented, but they provide guidance, covering the areas which are vital for successful quality provision and learning environments in higher education. The ESG should be considered in a broader context that also includes qualifications frameworks, ECTS and diploma supplement that also contribute to promoting the transparency and mutual trust in higher education in the EHEA. (Revised ESG p 3, 2014)

The ESG for internal quality assurance have changed from seven to ten and presently suggests more explicitly support for an integration with student-centred learning, the development of pedagogics (teaching and learning), and a cyclical approach to both internal and external quality assurance. ${ }^{5}$ Another change is a more specific approach for monitoring of students' progression path and future careers.

The revised ESG reflect a development towards a more student-centred focus of quality assurance and higher education. The now ten ESG for internal quality assurance are both inclusive and responsive, and have been formulated in a way that IQA ESG can be applied to diversified higher education, i.e. supporting widening access and participation, and tracking the progression path of student to improve not only the student experience, but learning and teaching. The revised ESG support a paradigm shift towards developing higher education systems and institutions that are "fit for purpose" for students and stakeholders and assist the creation quality assurance policies and practice that are able to reflect the diversity of courses, programmes and institutions that provide education in different modes and media.

\section{Changes and Challenges for the European Higher Education Landscape Have Implications for Quality Assurance}

There is no common definition for quality assurance (Williams 2011), or the closely related concepts of quality enhancement, quality culture, evaluation, accreditation, accountability, transparency (ENQA 2014) and transparency tools (Hazelkorn et al. 2014) — and perhaps the lack of definition is a strength as this supports adaptability rather than conformity. Diversity in approach and understanding is not surprising, as there are over four thousand higher education institutions in the 48 countries that are part of the European Higher Education Area ${ }^{6}$ All are operating within legal and administrative frameworks of their national or regional higher education systems

\footnotetext{
${ }^{5}$ New ESG 1.9 On-going monitoring and periodic review of programmes, and 1.10 Cyclical external quality assurance.

${ }^{6}$ The European Union's High-Level Group on the Modernisation of Higher Education (2014).
} 
and they vary in size and mission. The implementation of the Bologna Process was designed to create a competitive and flexible European Higher Education Area through e.g. introducing three cycle systems, curriculum development, learning outcomes linked to qualification frameworks, ECTS for transfer and accumulation and the diploma supplement, all to increase transparency and flexibility. These very ambitious goals may not have been achieved in all 48 countries, but they have supported and highlighted the importance of higher education for the future of Europe in all countries. The Bologna Process has created a common European language or terminology - albeit with national or institutional interpretations (Trends 2010). A considerable diversity remains in European higher education, "between systems, which retain their own characteristics, between institutions, which vary in size, mission and profile and even, within institutions." (Reichert 2009). Challenges remain, as the economic crisis, globalisation, demographic changes and technological developments have an impact on the national higher education systems. The European language is the ESG among the growing number of quality assurance professionals, but the articles in this chapter indicate that not all stakeholders are fluent in it. The proposal for the revised ESG can be seen as addressing the growing diversity by creating, on the one hand, a joint understanding and, on the other hand, supporting a diversity of approach to quality assurance in European higher education.

It is difficult to consider the quality and the quality assurance of European higher education without reflecting on not only the changing global reality for higher education systems, but also the complexity of its three missions: education, research and service to society. The repeatedly quoted challenges of massification, technological changes/digital learning environments, globalisation, financial crisis, changing demography, high youth unemployment rates and whole employment sectors that are under deconstruction present a complex set of challenges for all European HEIs. For quality assurance to support the continuous development of higher education institutions, their educational offer and the higher education systems in an ever changing global higher education landscape, it seems essential that it is built on trust, flexibility, and adaptability, and that the ESG form the common "language".

New approaches to learning and teaching have almost exploded in this decade, e.g. flipped classrooms, blended learning, MOOC, and OER (European Commission JRC Report 2014)_practices that are seen by some as opening up higher education. Other developments are in the area of transnational education, where two policy areas of quality assurance and internationalisation intersect. The increased focus on learning and teaching and student-centred learning raise a key question on the potential requirement to develop specific quality assurance for specific higher education offers such as open and distance learning, provision of international or transnational education (joint programmes and degrees), continuing education including LLL provision, bridging courses, etc. Do new forms of learning and teaching delivery to a diversified student population (full-time, part-time, national/international or non-traditional students) in the mode of traditional campus education, distance or e-learning, MOOCs, SPOCs or in a flipped classroom 
together with many new transnational/joint/cross-border initiatives pose challenges for quality assurance? In recent years, a great number of European projects and initiatives have looked at developing specific quality assurance activities (e.g. E-xcellence, EFQUEL, EQUAL, EQUIPE, SEQUENT, and the ARDE project on quality in Doctoral Education) for specific types of provision of higher education. It raises the issue if a diversified European higher education landscape also demands diverse and targeted quality assurance processes, thus making it very complex to develop a common understanding of quality assurance, and how HEIs can manage a great number of different practices. Are modes of teaching or types of students more important? Are the challenges diversification pose for the qualitative development of higher education not reflected sufficiently in the revision of the ESG? Would it not be better to focus on principles of quality assurance rather than on the mode of delivery or the specificities of different student populations or institutions?

The Bologna Process was initially a collection of separate developments initiated in earlier decades that together have been developed over time to support the qualitative development of learning and teaching and student-centred learning by creating a framework as mentioned above. The framework has been developed to promote transparency, accountability, and the quality of European higher education, but discussions at the Future of Higher Education Conference, 2014 show that this vision is not a reality, yet. The understanding of this long-term vision may easily be lost with the arrival of new generations of ministers, students, academics, and policy makers, and a much more utilitarian approach to the development of higher education emerges, as other challenges seem to overshadow the European vision.

European higher education is in the middle of a paradigm shift (EUA 2014), and looking back at fifteen years of higher education reforms, it is clear that much has been done at European, national and institutional level to address and support Bologna inspired changes not least in quality assurance. The name Bologna Process has perhaps lost part of its meaning for the vast majority of students in European higher education who now study within Bologna structures. The collective memory is often short and it would therefore be important to reinforce the visionary aspect for each new generation.

Many European funded higher education projects, and in particular the different rounds of EUA's quality assurance projects have concluded that leadership is an essential success factor for the development and implementation of European strategies and policies. Successful implementation of policies and activities like quality assurance interlinks strategic development ${ }^{7}$ and engaged leadership, and is another potential explanation for the perceived success of the European quality assurance development. Renewed visions and engagement are needed as research indicate that the original visions for quality assurance is not yet a reality everywhere, despite the well-documented progress.

\footnotetext{
${ }^{7}$ EUA Examining Quality Culture (2009-2012).
} 


\section{Conclusion}

The 2014 FOHE Researchers' Conference indicates that behind the European quality assurance success story a much more complex picture of quality assurance is emerging. An image emerges that points to both convergence and divergence in approach and to remaining challenges - and this is perhaps not surprising given the diversity of the European Higher Education Area and the global challenges.

In the past decade, much research and a great number of projects and studies have been carried out to track the development of quality assurance, quality culture and the use of transparency tools. The sheer volume of activities and projects indicate that there is great engagement and many European stakeholders who "practice as they preach". These projects show that development of quality assurance is based on a number of different tools in order to triangulate information collected through formal and informal tools and ex ante and ex post approaches. There is agreement that evaluation results have to be used, results published, and quality assurance must include feedback loops and be based on a clear understanding of responsibilities. However, these tools and practices do not have a great impact, nor do they create a quality culture if academics and students are not engaged in self-reflection.

Transnational quality assurance has both benefits and challenges for higher education institutions, and its use is often related to the implementation of an internationalisation strategy, thus linking two important parts of the Bologna Process. In many countries, however, the national legislative framework is inhibiting such reviews, but the Szabo article indicates that this does not prevent higher education institutions from engaging.

All the papers in the quality assurance sessions clearly show the importance of engaging students and staff at institutional level, but also a need for flexibility and transparency in policies and practices.

The FOHE 2012 Researchers' Conference recommended a revision of the ESG, a revision that will be presented at the Yerevan Ministerial meeting. The revision is an example of how quality assurance is "work in progress" that requires the continuous development and evaluation of established policies and practices in order to make it an integral part of the higher education framework. The revised ESG indicate a shift towards addressing the need to have a diversity of higher education provision. Regardless whether it is provided for traditional full-time or part-time students, or for national or international students at the bachelor- master or doctoral level, or the provision of lifelong learning or continuing education; whether the teaching mode is campus or non-campus based or jointly provided at institutional level or transnationally. Quality assurance is therefore an integrated part of the dialogue on the progress of creating a European Higher Education Area that other continents will continue to look at with interest. Quality assurance is an on-going process where the interaction between the internal and external processes is essential and where a multifaceted and transparent approach seems essential and where the constant dialogue ensures that the stakes do not encourage a compliance 
culture. Nevertheless, it can be expected that both external and internal, national and institutional quality assurance also in the coming decade will continue on its winding road:

full of twists and turns, that took them - variously - from evaluation to accreditation; from assigning ratings to subjects or study programmes to abandoning such a process; from the evaluation of subjects or programmes to the evaluation of institutions, and back to subjects or programmes (Sursock 2011).

It can be hoped that the engagement of the different quality assurance communities will continue to grow, and that in the next decade focus will move from form to content and that a continuous dialogue will continue on how best to achieve that. This discussion should engage ever-larger numbers of academics and students in quality enhancing discussions on such aspects as learning and teaching, student-centred learning, curriculum development, learning outcomes, recognition, ECTS and the Diploma Supplement. It is to be hoped that the dialogue will engage or re-engage ever larger circles of higher education stakeholders and that the positive organizational experiences from the European quality assurance community can contribute to the next phase of development of the European Higher Education Area.

Open Access This chapter is distributed under the terms of the Creative Commons Attribution Noncommercial License, which permits any noncommercial use, distribution, and reproduction in any medium, provided the original author(s) and source are credited.

\section{References}

BPMC, Bologna Process Ministerial Conference. (2003). Realising the European Higher Education Area Communiqué of the Conference of Ministers responsible for Higher Education. Retrieved from http://www.ehea.info/Uploads/about/Berlin_Communique1.pdf. Accessed 20 Oct 2014.

Curaj, A., Scott, P., Vlasceanu, L., \& Wilson, L. (eds.) (2012) European Higher Education at the Crossroads Between the Bologna Process and National Reforms, Dordrecht.

EC European Commission JRC Report. (2014). State of the art review of quality issues related to open educational resources (OER) http://is.jrc.ec.europa.eu/pages/EAP/documents/ 201405JRC88304.pdf. Accessed on 22 Oct 2014.

ENQA, European Association for Quality Assurance. (2005). European standards and guidelines for quality assurance in the European Higher Education Area. Retrieved from http://www. enqa.eu/index.php/home/esg/. Accessed on 7 Nov 2014.

ENQA, European Association for Quality Assurance. (2011). Mapping the implementation and application of the ESG (MAP-ESG Project). Retrieved from http://www.enqa.eu/index.php/ publications/papers-reports/occasional-papers/. Accessed 20 Oct 2014.

ENQA, European Association for Quality Assurance. (2014). Retrieved from http://www.enqa.eu/ indirme/papers-and-reports/occasional-papers/Transparency\%20of\%20European $\% 20 \mathrm{higher} \%$ 20education\%20through\%20public\%20quality\%20assurance\%20reports\%20(EQArep).pdf. Accessed on 21 Oct 2014. 
EUA, European University Association. (2014). A twenty-year contribution to institutional change. Retrieved from http://www.eua.be/Libraries/Publications_homepage_list/20_years_ of_IEP.sflb.ashx. Accessed on 25 Jan 2015.

EUR, European University Association. (2009). Improving quality, enhancing creativity: Change processes in European higher education institutions. http://www.eua.be/Libraries/Quality_ Assurance/QAHECA_Report.sflb.ashx. Accessed 20 Oct 2014.

European Association for Quality Assurance in Higher Education, European Students' Union, E. U.A., European Association of Institutions in Higher Education, Education International, BUSINESSEUROPE, \& European Quality Assurance Register for Higher Education. (2014). Revised version standards and guidelines for quality assurance in the European Higher Education Area. Retrieved from https://revisionesg.files.wordpress.com/2014/10/esg-draftendoresed-by-bfug.pdf. Accessed 17 Nov 2014.

Hazelkorn, E., Loukkola, T., \& Zhang, T. (2014). Rankings in institutional strategies and processes: impact or illusion? Retrieved from http://www.eua.be/Libraries/Publications_ homepage_list/EUA_RISP_Publication.sflb.ashx. Accessed 17 Nov 2014.

Loukkola, T. (2012). A snapshot on the Internal Quality Assurance in EHEA. In A. Curaj et al. (Eds.), European Higher Education at the Crossroads between the Bologna Process and National Reforms (pp. 303-316). Dordrecht.

Loukkola, T., \& Sursock, A. (2014). In EUA, European University Association. 2014. A twenty-year contribution to institutional change. Brussels, Belgium: European University Association asbl.

Loukkola, T. \& Zhang, T. (2010). Examining quality culture: Part I Quality assurance processes in higher education institutions EUA, Brussels 2010. http://www.eua.be/pubs/examining quality_culture_part_1.pdf. Accessed 20 Oct 2014.

Reichert, S. (2009). Institutional diversity in European higher education: Tensions and challenges for policy makers and institutional leaders. EUA.

Smidt, H. (2012). Education as transformation-Transforming European Higher Education. In A. Curaj et al. (Eds.), European Higher Education at the Crossroads between the Bologna Process and National Reforms (pp. 141-151). Dordrecht: Springer.

Stensaker, B. (2011). Accreditation of higher education in Europe-moving towards the US model? Journal of Education Policy, 26(6), 757-769. http://www.tandfonline.com/doi/pdf/10. 1080/02680939.2010.551785

Sursock, A. (2011). Examining quality culture: Part II Processes and tools-Participation, ownership and bureaucracy. Retrieved from http://wwweua.be/pubs/examining_quality_ culture_part_ii.pdf. Accessed 20 Oct 2014.

Sursock, A. (2012). Quality Assurance and the European Transformational Agenda. In A. Curaj et al. (Eds.), European higher education at the crossroads between the Bologna Process and National Reforms (pp. 247-266). Dordrecht.

Sursock, A., \& Smidt, H. (2010). Trends 2010: A decade of change in European higher education. Retrieved from http://www.eua.be/Libraries/Publications_homepage_list/Trends2010.sflb.ashx. Accessed 20 Oct 2014.

The European Union's High-Level Group on the Modernisation of Higher Education. (2014). Report on 'new modes of learning and teaching in universities'. Retrieved from http://ec. europa.eu/education/library/reports/modernisation-universities_en.pdf. Accessed 22 Oct 2014.

Williams, P. (2011) Quality assurance: friend or Foe? In Robert, B., \& Observatory of the Magna Charta Universitatum Observatory Magna Charter Universitatum (eds.). Contemporary Threats and Opportunities: Academic Freedom and Institutional Autonomy within the Context of Accreditation, Quality Assurance and Rankings. Proceedings of the Conference of the Magna Charta Observatory. 15-16 Sept 2011 http://www.magnacharta.org/observatoryPublication. aspx?uid $=\{$ ee752d70-7afe-484a-89a9-f3e76d7006d2 $\}$. Accessed 21 Oct 2014. 